\title{
O papel do não europeu na crise e renovação do último Husserl
}

The role of the non-European in the crisis and renewal of the last Husserl

DOI: 10.12957/ek.2021.60855

\section{Caio Lívio Sulpino Dantas ${ }^{1}$}

Universidade Federal da Paraíba

caiosuldantas@gmail.com

https://orcid.org/0000-0002-8799-0822

\section{RESUMO}

Para Edmund Husserl, a humanidade ocidental ou europeia teria surgido a partir da filosofia grega, e, portanto, seria uma humanidade teorética ou científica. Em razão desta característica alcançada ao longo de sua história, o continente espiritual Europa, regido pelo fazer filosófico, comportaria uma motivação teleológica própria de realizar-se por norma ideativas. Esta motivação diz respeito ao telos gestado na Grécia antiga e atualizado, agora, em uma crise de sentido que atinge o espírito da Europa como uma enfermidade. Não obstante serem distintas, Husserl crê que demais culturas pré ou não cientifico-filosóficas, ou seja, pré ou não europeias, seguem cobiçando o horizonte ideativo europeu por força de uma tarefa maior, e que conduziria todo o mundo ao sentido desta crise. Se a crise da ciência europeias reside na transposição da tarefa grega da razão sem levar em consideração a sua nuance originária, com o presente artigo discutiremos brevemente o mandado desta tarefa infinita em vista da diversidade das demais culturas.

Palavras-chave: Husserl. Fenomenologia. Crise. Telos. Enteléquia.

\footnotetext{
${ }^{1}$ Mestre em filosofia pela UFPB (2019). Possui graduação em Direito pela UEL (2016), com especialização em estudos críticos do direito.
} 


\title{
ABSTRACT
}

For Edmund Husserl, western or European humanity would have emerged from Greek philosophy, so, therefore, it would be a theoretical or scientific humanity. Due to this characteristic achieved throughout its history, the spiritual continent of Europe, governed by philosophical practice, would have a teleological motivation of its own to be realized through ideational norms. This motivation is related to the telos gestated in ancient Greece and updated, now, in a crisis of meaning that strikes the spirit of Europe as an illness. Despite being distinct, Husserl believes that other pre- or non-scientific-philosophical cultures, that is, pre- or non-European, continue to covet the European ideational horizon by virtue of a greater task, and that would lead the whole world towards this crisis. If the science crisis resides in the transposition of the Greek task of reason without taking into account its original nuance, with this article we will briefly discuss the mandate of this infinite task in view of the diversity of other cultures.

Keywords: Husserl. Phenomenology. Crisis. Telos. Entelechy.

\section{1) INTRODUÇÃO}

\begin{abstract}
Há nela [Europa] qualquer coisa singular, que todos os outros grupos humanos sentem também em nós como algo que, abstraindo de todas as considerações de utilidade, se torna para eles, um motivo para sempre se europeizarem, apesar da vontade inquebrável de autopreservação espiritual, enquanto nós, se bem nos compreendermos a si próprios, jamais nos queremos, por exemplo, indianizar. Quero com isto dizer que sentimos (...) que, na nossa humanidade europeia, está inata uma enteléquia que rege, de ponta a outra, a deveniência das formas europeias e lhes confere o sentido de um desenvolvimento para uma de vida e de ser ideias, como para um polo eterno (HUSSERL, 2014, p. 122)
\end{abstract}

É importante frisar a assertiva de Husserl de que a humanidade ocidental ou europeia teria surgido a partir da filosofia grega e, portanto, seria uma humanidade teorética ou científica (HUSSERL, 2012, p. 4). O surgimento da racionalidade filosófica, bem como o surgimento de uma consciência científica, seriam a marca espiritual da cultura europeia, seu telos (finalidade) e entelekheia (atualização, consumação).

Quando destaca a cultura europeia frente às demais, sob o argumento da particularidade filosófica, Husserl se pergunta pela casuística da história. Ele contrasta à alternativa do paradigma greco-europeu a convicção terminativa do devir científico. 
O filósofo reconhece que a filosofia veio a ser europeia, mas deseja assimilar a relação deste devir com o projeto científico desenvolvido, se haveria no devir filosófico um mero acidente ou uma atualidade mais ampla. A partir deste contrastes, poderemos traçar algumas análises aos povos não europeus e, em especial, latino americanos.

De início, Husserl assume um conceito aristotélico para explicar o advento congregador da racionalidade filosófica europeia, o conceito de enteléquia. Do grego, entelekheia pode ser traduzida por consumação ou atualização. Trata-se da designação da causa final de um ato, potencialidade ou tendência de acabamento, que tenciona temporalmente toda forma originária de ser. De certo modo, os vários movimentos de atualização da enteléquia só são possíveis porque todo corpo ou ente guarda em si, baseado na teoria aristotélica, um telos de acabamento.

Por exemplo, na seguinte passagem, presente em De anima (parte II, 412a28), Aristóteles nos diz: "não é preciso explicar se alma e corpo são uma unidade - (...) nem se a matéria de cada coisa e aquilo de que é matéria [o são] - pois, já que se diz unidade e ser de muitos modos, o mais apropriado deles é a atualidade [entelekheia]" (ARISTÓTELES, 2012, p. 72). Apesar do referido conceito estar mais ligado ao realismo do mestre de Estagira, enquanto tendência natural dos organismos se realizarem entre ato e potência, verifica-se o seu bom uso na compreensão de qualquer conceito gradativo de aperfeiçoamento.

Husserl (2012, p.11) se utiliza deste conceito para significar o momento europeu, sugerindo que este momento é a atualização do fenômeno grego de presentação do potencial da filosofia. Deste passo decorre a conscientização do movimento histórico de revelação da razão universal, 'inata' como tal à humanidade, mas possuidora de uma cultura matriz. Husserl, então, pondera a eventualidade do encontro entre o telos gestado na Grécia antiga, com a origem pré-socrática da filosofia, e efetivado na Europa, atendendo à coligação de causa e efeito na enteléquia. Será mesmo uma eventualidade o reencontro europeu com a filosofia clássica no Renascimento? Ou terá sido acaso os mil anos de filosofia cristã no processo de constituição do continente espiritual?

Muito embora afirme o caráter europeu desta realização absoluta, os escritos de Husserl são dotados de um preconceito quanto à univocidade europeia da tarefa da razão, o que exporemos mais àfrente. Sua questão é a questão da identificação da trajetória da Europa com uma epistemologia universalmente válida. Para tanto, compara 
as culturas distintas da europeia, segundo o âmbito teleológico, procurando suas diferenças. Por exemplo, “um tipo antropológico meramente empírico como a 'China' ou a 'Índia"” (HUSSERL, 2012, p. 11), conforme rotula estas culturas, não pertenceriam ao projeto filosófico em si, senão através da europeização. O ser europeu de um lado, e a europeização distribuida ao resto do mundo do outro.

Husserl persegue esta comprovação do telos filosófico na história da Europa, o que corroboraria com a especialidade da racionalidade una, e poderia ainda sustentar a crença na metafísica. De certo modo, dar sentido a este idealismo pregresso, renovandoo, é a vontade firme de aclarar uma contradição existencial do universalismo histórico. Husserl pretende verificar se é "em si a vigência de um sentido absoluto, pertencente ao sentido do mundo, e não um sem sentido histórico desse mesmo mundo" (HUSSERL, 2012, p. 11). Mas ao afirmar o levante de uma cultura pela razão absoluta e universal, também está admitindo que qualquer outra cultura o desejaria. Como também, pode-se questionar se qualquer outra possibilidade de destino "não filosófico" viria a constituir nosso mundo cultural.

\section{2) DESENVOLVIMENTO}

O entrelaçamento husserliano entre o mandatário europeu da filosofia, e o que talvez seja um problema ingênito da razão - a saber, a impermanência de um postulado epistemológico único - conduz o pai da fenomenologia a pensar a relação entre diferentes culturas, mas admitindo a Europa como o cerne da discussão.

Husserl (2014, pp.39-40) já indicara esta análise comparativa em artigos sobre renovação ética e cultural que escrevera ainda na década de vinte para a revista japonesa The Kaizo. Em um destes artigos, Renovação como problema ético individual, de 1924, discute a forma de vida da 'humanidade autêntica', ligada à ideia de homem de razão (animal rationale), que contrapõe ao homem paradisíaco.

Para ele, o homem paradisíaco é caracterizado por uma infalibilidade instintiva idealmente adaptada às circunstâncias, e, no entanto, é um homem como que cego e contingente, porque desprovido de razão, evidência crítica e justificação. Ou seja, tratase de um homem não filósofico, um selvagem desprovido de racionalidade dirigente e justificada aos moldes europeus. Quanto ao homem de razão, este cria sua referência de 
si a partir da subjetividade (auto reflexão), com base nas possibilidades que pertencem à sua essência, sua autovaloração judicativa e autodeterminação prática. Este homem de razão, "tanto mais decididamente adota na sua vontade a forma racional, reconhecida enquanto tal, da vida e dela faz a lei inabalável da sua vida: tanto mais perfeito ele é" (HUSSERL, 2014, p. 41).

No mínimo, com esta diferenciação, Husserl está reportando ao quanto o surgimento ou justificação do homem de razão discrimina ou nega evolutivamente a designação de homem paradisíaco, por não operar pela idealidade da razão. A despeito das noções bioevolutivas ou antropotécnicas não serem objeto de nossa discussão, a noção da enteléquia da cultura está visivelmente presente na visão de Husserl acerca do homem racional. Isto é notável ao falar que o "a priori que nele [homem de razão] repousa cria-o, portanto, na sua forma mais originária, a partir de si próprio, enquanto seu 'eu verdadeiro' e seu 'melhor eu'” (HUSSERL, 2014, p. 42).

O que está se delineando aqui é a importância da significação, do ‘tornar-se’ em moldes ideais, fundado na essencialidade do espírito pelo que lhe é inato, como entende que deva ser o costume do homem de razão, de deveres, de tarefas. E, como se vê, é sempre através da condição racional, no olhar autocentrado, que se busca a perfeição, não explicitamente a partir de de uma mirada externa.

A temática ética se faz presente. Em especial a ética deontológica de Kant, a partir da qual Husserl escreve linhas de teor: "só é bom o que se justifica absolutamente, portanto, não aquilo que se justifica apenas na sua singularização, mas antes no universo de possibilidades práticas e a partir de uma vontade universal”' (HUSSERL, 2014, p. 42) e "só pode ser 'verdadeiro homem', valorado como pura e simplesmente bom, porquanto se submeta voluntariamente ao imperativo categórico" (HUSSERL, 2014, p. 42-43). Novamente, o ideal absoluto, convicto da perfeição da faculdade racional, é dimensionado como fim último, livremente normativo, mas empenhado em salvaguardar uma pretensão universal.

Nesta ocasião, Husserl (2014, p.43) descreve a subjetividade do ente racional, encetado na crença do devir absoluto da razão, pelo que todo o amparo do sentido de mundo está dado no tempo futuro, ao qual a razão conduziria. O sugerido homem paradisíaco, assim, resta superado, inclusive de um ponto de vista ético (como dever de superação em nome da boa razão), e aquele que o supera é o homem racional (europeu). 
Entretanto, uma grande frustração na performance do autogoverno da razão inclina Husserl a perguntar onde está o erro cometido no exercício do dever pela ciência.

Aqui, o homem artífice, homem racional, que faz de si um referencial histórico autocentrado, encontra-se dividido em si e entre homens. E, tal segmentação frustrante não está muito distante da avidez por autenticidade na diferença. A negação de Husserl ao objetivismo, como tendência alienante apontada durante toda a sua trajetória, em parte pode decorrer da percepção do quanto este modelo desfragmenta as marcas subjetivas na cultura e na ciência. Vale dizer que há uma suspeita por parte do filósofo de que a subjetividade racional ou científica, que, de algum modo, veio a incorrer no objetivismo, tenha acabado por distanciar o homem de sua raiz paradisíaca, produzindo ceticismo em relação à sua própria cultura.

Em outro artigo à revista The Kaizo, chamado Renovação e Ciência, de 1922/1923, Husserl outra vez persegue o ideal de uma comunidade autenticamente humana, que reside no espaço comum entre culturas, sob a forma de sujeito de consciência absoluta (HUSSERL, 2014, p. 53), isto é, o sujeito que faz ciência das relações que estabelece. Ao ponderar a evolução de uma comunidade éticaa saber,uma comunidade de perfil kantiano, baseada no imperativo categórico, e que visa à formação ético-moral voltada à uma ideia-final (HUSSERL, 2014, p. 60), Husserl advoga em causa da execução da tarefa científica dentro da noção de subjetividade.

\begin{abstract}
Assim como os sujeitos singulares e a subjetividade comunitária estão conscientemente retrorreferidos a si próprios e têm a sua forma suprema em uma subjetividade que a si se conhece, valora e quer, certamente a si própria se forma segundo normas categóricas que para si própria põe, também a ciência principal desta subjetividade, enquanto saber que dá forma a si próprio, está retrorreferida a si mesma, e isto quer dizer: ela deve chegar a perguntar - e a responder cientificamente - em que medida a Ciência, especialmente a ciência ética, tem uma função ética na vida comunitária e singular; (...) a questão de saber em que medida a ciência ética é, necessariamente, um meio, que deve desenvolver-se em uma comunidade para que ela própria possa atingir níveis principalmente mais elevados de valor (HUSSERL, 2014, p 61).
\end{abstract}

Como se perseguisse o atestado axiológico da ciência por via de dúvidas metódicas - expressando a linguagem científica no seu filosofar, nunca plenamente confirmativa, mas gradualmente cogitante, à maneira cartesiana - não à toa Husserl destaca a diretriz ética (ciência da ética) como a via de determinação espiritual de sua cultura, a cultura científica. Se por um lado este marco cultural vem colaborar com a 
autoridade da técnica, com vistas a integralizar o homem de razão e sua visão de mundo, restabelecendo-o como uma subjetividade própria, recordemos que outras humanidades e culturas faziam frente a esta tendência científica dentro de um pensamento, tido por exclusivo. Do oposto não haveria contraste àquela subjetividade ético-científica.

Mas o contraste entre culturas, quiçá entre subjetividades, precisa ser solucionado a fim de alcançar termos com o universalismo do homem científico. Nesse contexto, além de buscar reconstituir a autenticidade cultural europeia fortalecendo seu sentido, Husserl proverá resposta às outras culturas com as dfinições de 'pré-cientificidade' e de 'não cientificidade'. É o que se verifica no artigo Tipos Formais da Cultura no Desenvolvimento da Humanidade, também para a revista Kaizo, do mesmo período, quando Husserl (2014, p. 88) faz referência, agora, aos povos antigos (babilônios, egípcios, chineses e indianos), no tocante à busca teórica rigorosa.

Husserl diferencia o conhecimento avulso (o qual entende presente nessas culturas distintas) do modo da universalidade científica (o qual não se faria presente nelas por si). Neste artigo, ele afirma que um agir especial - um ego cogito - origina a crença definitiva na busca universal da razão. Em oposição a este modelo, outro há, que é teológico ou mitológico, o qual parte de convicções gerais enraizadas na tradições antigas (HUSSERL, 2014, p. 90).

Diante deste primeiro modelo de fundamento, que é lógico-judicativo, sujeito a normas de intelecção, a diferença entre ambos está "na passagem de uma visada judicativa não intelectiva para a intelecção" (HUSSERL, 2014, p. 92), ou seja, na preferência pelo visado intectual justificado; em comparação à simples visada do intelecto costumeiro, injustificado na cientificidade.

Embora todos os povos reconheçam coisas semelhantes no mundo, tão só quando passam pela visão judicativa científíca, justificam sua visão como algo objetivamente comum. E, neste momento, “abre-se um domínio da verdade que cada um traz para o seu olhar, que cada um, olhando, pode efetivar em si, cada um a partir de cada círculo cultural, amigo e inimigo, grego ou bárbaro (HUSSERL, 2014, p. 92). O encontro entre o modelo justificado por evidência aureflexiva (cogito), e o modelo de convicções tradicionais, delineia o ser da cultura científica (wissenschaftlich), bem como delineia o que é cultura não científica (unwissenschaftlich) e pré-científica (vorwissenschaftlich). 
A distinção, pois, entre o científico, o pré científico e não científico, coloca-se entre a experiência e a técnica. Pois em primeiro lugar deve ficar claro que "o interesse teórico não é o círculo da experiência (...). Só a ciência que se mostra já preparada e que dá frutos técnicos desperta necessidades científicas a partir da técnica" (HUSSERL, 2014, p. 95). Pode-se depreender desta análise que o 'não-' e o 'pré-', mas também o homem paradisíaco, são distinções que eclodem do advento formal da narrativa histórica distintiva, com a qual Husserl respalda o advento filosófico-científico no devir Europa: “[...] sob a designação de Filosofia, a ideia de ciência rigorosa a partir da razão livre é a ideia cultural abrangente e universalmente dominante” (HUSSERL, 2014, 106).

Não basta ciência, é preciso uma ciência que aja sobre a ciência da técnica. Uma dupla ciência, ciência de rigor, como epistemologia que veio a ser, sincronicamente universal e dominante, devido a um preparo autoelucidativo - em linhas gerais, como discorreu em todas as suas obras desde as Investigações Lógicas, esta ciência visada não é uma ciência comum, mas a cientificidade do método, ancorada na metafísica. Este préparo da ciência metodológica gerou uma condição de superação a todas as outras formas de saber. Não obstante Husserl aceite o valor cultural diverso, i.e, a diversidade do outro, o filósofo enseja o sentido da forma científica normativa como fim das demais formas culturais, devido à sua qualidade inata.

Da menção ao telos filosófico, que conduz à diferenciação da mera experiência com o conhecimento, temos a observação do sentido de gradação de algo, isto é, uma consciência histórico-temporal evolutiva por etapas ou épocas. E, partindo de uma tal consciência é que Husserl compreende o tempo e a história, como absoluto no qual se constituem objetivamente uma natureza, homens, culturas, etc, dirá Ricoeur (2009, p. 16). Mas também tais separações se constituem nesse processo, é preciso deixar isto claro.

A enteléquia de Husserl se aproxima da ideia de uma consciência histórica. Como uma forma de compreensão da razão na história, de modo semelhante a Hegel, ou como uma progressão autoelucidativa, possuidora de um mandatário em particular. O que Husserl nos está descrevendo é o processo de universalização das partes em um todo, mas com sentido para a tendência agregadora e universalista da cultura europeia.

Esta fixação, o pensador argentino Mario Casalla atribui ao exclusivo pensamento centrista europeu (germânico em particular), sob influência da metafísica, 
onde tudo o mais que não participasse diretamente deste "centro" era tido por caótico e desqualificado (CASALLA, 1977, p. 37). Casalla nos dirá mesmo que a filosofia e a ciência são as maiores expoentes da visão europeia de mundo: divide-se o mundo, então, em uma cultura científica ou de ideias, e uma cultura pré-científica ou extra-científica. O que serviria para separar o ocidente e o oriente. O civilizado (desejável) e o bárbaro (rechaçável) - ou racional e paradisíaco.

Esta separação mais tarde se fará inter-hemisférica e intranacional, para terminar com a dicotomia cultura e incultura. A tarefas infinitas conduziriam à expansão infinita: ideais infinitos para a síntese cada vez mais vasta de nações. A razão, grega, assim, separa e privilegia (CASALLA, 1975, p. 56-57).

Também Wallerstein esboça criticamente a fisionomia do pensamento tido por eurocêntrico do período. Pela ótica de autores filiados ao orientalismo, este tangencia o modo de descrição cultural retratado por Husserl e demais pensadores do período: "a base da explicação desenvolvida era de uma simplicidade notável. Só a 'civilização' europeia, com raízes no mundo greco-romano antigo (...), poderia produzir a 'modernidade"' (WALLERSTEIN, 2007, p. 66). Já Alejandro Serrado Caldera, pontua que especialmente no caso europeu, "em virtude de uma concepção etnocêntrica, o regional foi assumido como o universal (...). Se as outras regiões tiveram algum significado para a Europa foi exclusivamente no que respeita à relação colonial ou comercial (CALDERA, 1984, p. 55).

Assim, é importante ressaltar como essas visões de Husserl foram tomadas ao longo do tempo por outros interpretes do conhecimento eurocêntrico. Acredita-se, hoje, haver superação ou esvaziamento desta crença em uma humanidade cooptadora das demais. No entanto, persiste a tese de Husserl da busca pela unidade da razão na forma de um primado científico-filosófico, do ponto de vista da justificação do conhecimento. Talvez não fosse esta a única razão com que os povos não europeus buscassem a Europa, considerando condições materiais. Contudo, haveria ainda sentido em pensar alguma centralidade para a cultura da razão, aqui entendida como o rastro da Grécia à modernidade?

Em um de seus últimos trabalhos, Husserl escreve a conferência $A$ Crise $d a$ Humanidade Europeia e a Filosofia, esta da década de 1930, na qual dirige a noção espiritual-histórica em vista de um conclusivo mal-estar espiritual. Nesta última fase de 
sua produção, conhecida como a krisis, Husserl (2014, p.116-117) descreve as ciências naturalistas-fisicalistas exatas dentro de um paradigma de domínio técnico sobre a natureza, mediante o sistema filosófico que rege o cientificismo.

Além disso, tais ciências europeias teriam rivalizado, no curso dos séculos, com as assim chamadas ciências do espírito, aquelas formas de saber baseadas na physis humana, em sua corporalidade, intelectualidade e intuicionismo próprio. O filósofo dirá que as ciências da exatidão, tais como a física, a lógica, a geometria, muito embora tenham levado a vitória na batalha contra as ciências espirituais, fracassaram no próprosito de uniformizar a filosofia. Pois não é viável o fazer científico plenamente desafetado da natureza espiritual do mundo. O conhecimento do mundo pelas ciências espirituais estaria afinado com a natureza de uma maneira que as ciências positivas não compreenderiam - ou, pelo menos, não no tocante ao que é vital.

Esta visão histórica, com efeito, tem a tendência de ver na história um produto normativo, sobretudo com interesse de autoconsciência do mundo circundante. Assemelha-se à via hermenêutica da fenomenologia, como a tomada por Heidegger, porém diversamente. Husserl opta por destacar o objetivismo (símbolo do pensamento em mal-estar ) de sua corrupção como tarefa infinita. Para isso, persegue uma normatividade diretora que não seja uma total escamoteação das elaborações da filosofia clássica, e nem tampouco a justificação da ciência tecnista moderna como único modelo.

Husserl reitera o teor dos demais escritos do período de 1920 e 1930, acerca da perda de norte da ciência. Mas, nesta última conferência, em particular, procura encaminhar uma solução dentro da análise histórica. Por detrás do argumento de renovação filosófico-científico, estaria o desejo de retorno às origens, de revitalização da autoridade guia da filosofia, visando superar o ceticismo e o sentimento de desencantamento espiritual, representantes da crise. De forma que, o distanciamento da physis ancestral, concebida como mundo da natureza espiritual, de toda manifestação corpórea, e da vontade anímica, conduziria pois, à crise da Europa. Este evento, tal como Husserl o entende, seria consequência de um preconceito funesto, ora reponsável pela “doença europeia", também com referência à crise (HUSSERL, 2014, p. 118).

Mas que preceonceito é este, e o que vem a ser a fonte da crise, nesta conferência? Entendida a noção de devir histórico também como uma representação, e mesmo uma escolha de sentido, Husserl entende que não é possível, sem prejuízos, 
inaugurar pela razão um mundo circundante dissociado de sua fonte constituidora de sentido. Onde a fonte primeira é a natureza e seu aspecto espiritual. Desta feita, vivenciar o mundo tal como os gregos é diverso da visão naturalista-objetivista com que os europeus têm vivivdo. O preconceito, pois, é este: embora tenha optado por dirigir seu mundo através da razão grega, a Europa praticou apenas residualmente a visão de mundo da filosofia grega, através de "uma representação do mundo" (HUSSERL, 2014, p. 118).

De certa forma, é uma violência injustificada transportar um mundo ao outro, um tempo ao outro, sem considerar os ecos desta transição. Não é equivalente tomar o mundo pela ciência que o constituiu, nas origens da cientificidade grega, sem reconhecer que se está diante de outro mundo circundante. Entre os pré-socráticos e Platão, toda uma convergência se deu no sentido de captar as particularidades de sua realidade. Seria este processo que Husserl desejaria ver repetido para salvaguardar a Europa: inovar a ciência considerando o mundo espiritual de seu tempo, como fizeram os gregos. Não a partir da ideia de um mundo objetivo, que teria sempre sido, em uma temporalidade absoluta. Ou seja,há algo de singular no legado espiritual-histórico do mundo grego, mas é preciso conquistá-lo, esta cientificidade singular, no novo.

Esclarecendo conceitos, o mundo circundante europeu, para o último Husserl é, pois, uma atualidade espiritual e histórica, cuja formação decorre de uma cadeia subjetiva em sucessão no tempo, e que se torna tema cultural dentro da macro-enteléquia daquele período. Em resumo, é a totalidade do culminar histórico numa dada observação. Por isto, em sequência, a cadeia de aparições espirituais de outros povos e culturas ganha conotações historicamente absolutas em função desta. Pelo que Husserl considera ser a necessidade do devir histórico, o devir europeu moderno, representar esta tarefa infinita.

Husserl quer salvar do preconceito positivista a verdadeira ciência, separando o cientificismo alienante do mundo espiritual - a partir do qual a ciência veio a ser. Ou seja, separação entre o pré-juízo (a ciência inata) e a vontade de ciência (o fazer humano da ciência). A partir da confecção husserliana de um sentido teleológico-histórico, fundido à espiritualidade, podemos compreender o modo como este lê as diferenças da pré cientificidade, culturas não científicas (em seu sentido próprio), e alteridade em geral. Sejam elas diferenças vindas de fora da cientificidade europeia, ou diferenças 
quanto ao saberes prévios à invenção da ciência, ou mesmo a negação à ideia científica.

O escopo de filiação à irmandade cultural infinita, para Husserl, somente pode ser universal na medida em que todas as humanidades estejam reunidas à história (metafísica) da tarefa infinita pela filosofia. O mecanismo se alastra tanto ao passado por exemplo, à ideia grega contribuíram os egípcios, os persas, e a eles seguiram-se os romanos, etc. - quanto ao futuro - o desejo de europeização, no sentido aqui tratado, atinge as nações presentes (HUSSERL, 2014, p. 121).

A vocação para a europeização é posta, inclusive, na qualidade de requisito máximo de intencionalidade, mediante explicação de que a permanente direção para a norma científica "habita interiormente a vida intencional das pessoas individuais e, a partir daí, das nações e das suas sociedades particulares e, finalmente, do organismo das nações ligadas" (HUSSERL, 2014, p. 124). Mas ainda com isto, Husserl não resolve as particularidades das culturas que julga distintas, seja por seu caráter pré-científico, seja pelo seu caráter não-científico, seja pelo seu caráter não histórico, ou não rigoroso.

Então, antes de avançarmos às conclusões destes limites de Husserl, recordemos algumas posições centrais da discussão até aqui: 1) há uma motivação teleológica no fazer filosófico incorporado pelo continente espiritual europeu; 2) esta motivação diz respeito ao telos gestado na Grécia antiga e atualizado, agora, em uma crise histórica e científica que atinge o espírito da Europa como uma enfermidade; 3 ) não obstante serem distintas, as demais culturas não cientifico-filosóficas seguem cobiçando o horizonte ideativo europeu por força de uma tarefa maior; 4) a crise das ciências europeias reside na transposição da tarefa grega da razão sem levar em consideração a sua nuance originária; 5) Husserl defende o mandado da tarefa infinita europeia, que reune as demais culturas, mediante um retorno ao fazer científico natural em sentido primeiro.

Dito isto, embora o pensamento histórico de Husserl se comprometa com um fazer incondicionado, o argumento da historicidade parece se sustentar "no 'ser efetivo' em sentido científico', assim como, de novo, na validade 'universal' para 'qualquer um"” (HUSSERL, 2014, p. 126). Ou seja, Husserl se limita a integrar diferentes subjetividades ao seu modelo. Por toda esta fase final da Fenomenologia de Husserl, uma forte ambivalência permeia o sentido de objetividade da ciência moderna, em seu interesse universalizante, como inimigo do fazer espiritual intuitivo e localizado. Mas também é muito presente a ambivalência no que diz respeito ao ser e não ser europeu, 
ser e não ser filosófico, ou científico, ou rigoroso.

Se este fazer local do conhecimento não científico (ou pré científico, ou até paradisíaco) é independente da cultura central, que permanece em crise, talvez a diversidade cultural tenha um trunfo em relação ao centro europeu, no tocante à solução do problema. Mas certamente um trunfo desprezado pelo próprio autor. Para que Husserl possa ser lido pelos não europeus de modo frutífero, à luz dos estudos decoloniais e de alteridade que tomaram o século XX, talvez devamos dar destaque ao ponto em que o filósofo está se contrapondo à prerrogativa da própria Europa, como continente que veio a adoecer.

\section{3) CONCLUSÃO}

A ciência objetivista, positivista, psicologista, composta de demais tendências limitadores, não pode ser interpretada exclusivamente na epistemologia que Husserl entendia ser central e renovável. Pois também esta epistemologia não volta os olhos a qualquer outro elemento senão à sua diretriz central. Seria este comportamento excessivamente autocentrado parte do problema?

Ao defender o valor da intuição sensível, e mesmo da opinião e imaginação em Fenomenologia, Husserl está abrindo portas ao retorno da visão grega de mundo espiritual. Não por reportar ao passado, mas por habilitar ver o mundo como uma região em aberto. Por esta ótica, aparece com mais vigor a comunhão de demais culturas com a Europa no pensamento husserliano, pois é mais universal a lógica do retorno à contemplação pré-científica que o retorno às raízes europeias como se já fossem infinitamente europeias a priori. É mais científica, em sentido de universalidade, a mirada intuitiva ao espírito do mundo que propriamente o fazer ou fundar metodológico?

O impasse entre o europeu e o não europeu está em que, sem a estruturação epistemológica não se tem a verificação capaz de distinguir o verdadeiro do falso, e que marca a cientificidade (europeia) desde Platão. O ambiente de indecisão às interpelações histórias para Husserl é, afinal, matizada por esses dois elementos: a cientificidade do espírito - que é onde a Fenomenologia se insere, para o último Husserl - e a cientificidade objetivista, com recurso à técnica. Mas também pelo elemento do que seja 
Europa em sua relação com as demais formas espirituais de saber, e daquilo que eventualmente não seja mesmo europeu, mas pertencente ao outro, ou simplesmente universal.

Despertar de uma vida mundana, disto depende a tematização do mundo. Decisão, dilema subjetivo, o circundar de mundo próprio ao Eu sensível, como a própria constituição de uma tarefa ideativa pertencente ao horizonte histórico. Pois, o que faz do telos filosófico decisivo é seu vir a ser em nome do ser-mundo. Mas este ser-mundo é precisamente abertura, e não necessariamente a própria história pregressa, que é a habitualidade mundana. A atualização da enteléquia, portanto, em uma temporalidade presente: "repousa no horizonte do mundo, mas são necessários motivos particulares para que quem está agarrado a uma tal vida mundana se converta e, por aí, chegue de algum modo a fazer dessa vida um tema" (HUSSERL, 2014, p. 130).

Unindo as pontas, Husserl está quase nos dizendo que o estado da enteléquia, quando se anuncia atualmente, é precisamente um convite a decidir a vida, como tema no horizonte do mundo, a partir do estado de coisas no agora. Da constituição de normatividade para a universalização desta normatividade em nome de um valor comum, perpetuam-se as cisões do saber e do ego como na "origem da cisão interna, posteriormente tão decisiva, da unidade do povo em cultos e incultos" (HUSSERL, 2014, p. 136). Portanto, a fonte do mal-estar espiritual, Husserl (2014, p. 147) deixa claro, nasce da unilateralidade ingênua da apreensão psicofísica de mundo - que toma a realidade espiritual como um anexo suposto dos corpos - mas também como qualquer outra unilateralidade produzida sem considerar a diferença.

O que não fica claro no discurso de Husserl é até onde ele aceita a unilateralidade não na relação da Europa com seu passado, mas na relação da Europa com seu presente. Do ponto de vista da filosofia do outro, em especial da filosofia latino-americana, o universalismo retratado por Husserl pode ser lido como uma unilateralidade do pensamento objetivista contra o próprio Husserl. $\mathrm{O}$ alvo da crítica pode ser direcionado ao próprio autor, por reduzir a filosofia à Europa, ou por defender sua expansão ao ponto de tomar as particularidades das demais culturas como una. Embora também não ousemos dizer que esta tendência à centralidade não ocorra, e ainda nos dias de hoje o comportamento se perpetua.

Contudo, outra leitura que se pode retirar da crise e renovação das ciências 
europeias, além da reinvenção da cientificidade pela filosofia, é análise da Europa como abertura também para a identificação autônoma de outras cientificidades. $\mathrm{Ou}$, como bem colocou Caldera acerca do motivo da filosofia latino-americana "é a procura de sua identidade e por isso a contribuição para forjar um homem novo e uma sociedade nova. Quer dizer, uma contribuição para a universalidade dada a partir de uma situação particular (CALDERA, 1984, p. 85).

Promessa esta que só pode se efetivar em nome de demais culturas e povos voltados ao ingresso em um elo científico ampliado. Em outras palavras, a enteléquia só pode ser entendida como conceito homogeneizador, com razão ética de ser, quando preceitua a multiplicidade do mundo espiritual de todos, que é o mundo da vida. Somente este Husserl pode dialogar com a possibilidade das identidades pluriculturais, a incluir a América Latina. Posto que, não nos parece superada a tendência husserliana de unificação cultural nestes apresentados artigos e conferências.

\section{Referências bibliográficas}

ARISTÓTELES. De Anima. Tradução de Marília Cecília Reis. São Paulo: Editora 34, 2012.

CALDERA, A. S. Filosofia e crise: pela filosofia latino-americana. Petrópolis RJ: Vozes, 1984.

CASALLA, M.C. Crisis de Europa y reconstruccion del hombre: un ensayo sobre Martin Heidegger. Buenos Aires: CASTAÑEDA, 1977.

, M. C. Husserl, Europa y la justificación ontológica del imperialismo. Revista de Filosofía Latinoamericana y Ciencias Sociales. Salta. n 1. 19-65. Janeiro/Junho, 1975

HUSSERL, E. A crise das ciências europeias e a fenomenologia transcendental: uma Introdução à filosofia fenomenológica. Tradução de Diogo Ferrer. Rio de Janeiro: Forense Universitária, 2012.

, E. Europa: crise e renovação. Tradução Carlos Morujão e Pedro Alves. Rio de Janeiro: Forense Universitária, 2014.

. E. A filosofia como ciência de rigor. Tradução de Albin Beau. Coimbra: Atlântida, 1965. 
RICOEUR, P. Na escola da fenomenologia. Tradução de Ephraim Alves. Petrópolis RJ: Vozes, 2009.

WALLERSTEIN, I. M. O universalismo europeu: a retórica do poder. Tradução de Beatriz Medina. São Paulo: Boitempo, 2007.

Recebido em: 15/07/2021 | Aprovado em: 05/08/2021

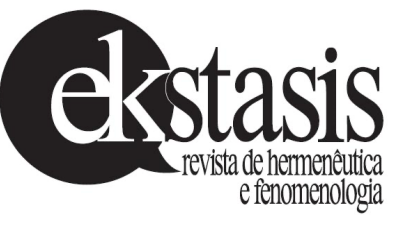

